\title{
Regulación de la videovigilancia en México. Gestión de la ciudadanía y acceso a la ciudad
}

\author{
Video surveillance regulation in Mexico. \\ Citizen management and access to the city
}

doi: http://dx.doi.org/10.32870/

espiral.v23i66.5301

Nelson Arteaga Botello

\begin{abstract}
Resumen
Se analiza cómo la videovigilancia pone los datos personales que administra en un espacio de indeterminación jurídica, y cómo genera procesos de clasificación social y espacial que derivan, algunas veces, en formas de exclusión social. La perspectiva que enmarca el estudio parte de definir la ciudadanía como la capacidad que tienen los individuos de construir espacios de autonomía y control frente a las lógicas de estratificación y dominación. Desde esta perspectiva se analiza cómo la pobre o inexistente regulación de las cámaras de vigilancia en México puede afectar el ejercicio de la ciudadanía.
\end{abstract}

Palabras clave: seguridad pública, videovigilancia, ciudadanía, clasificación social, privacidad.

\begin{abstract}
This paper analyze how the video surveillance puts the personal data that manage in a space of legal indeterminacy, and how generates process of social and space classification that derive, sometimes, in forms of social exclusion. The perspective that frame this study starts from defining citizenship as the capacity that individuals have to construct autonomy and control spaces against the stratification and domination logics. From this perspective, it's analyzed how the weak or inexistent regulation of video surveillance cameras in Mexico can affect the citizenship practice.
\end{abstract}

Keywords: Public security, video surveillance, citizenship, social sorting, privacy.

-Profesor-Investigador de la Facultad Latinoamericana de Ciencias Sociales (FLACSO), México.nelson.arteaga@flacso.edu.mx 


\section{Introducción}

Las primeras cámaras de vigilancia aparecieron en ciudades que funcionaban como destinos turísticos durante el verano, tanto en Europa como en los Estados Unidos. Su objetivo era detectar carteristas, pequeños defraudadores, comerciantes ilegales, así como disuadir comportamientos que alteraran el orden social (Hempel y Töpfer, 2009). Durante la ola de atentados terroristas que el Reino Unido vivió en las décadas de los ochentas y noventas, las cámaras de vigilancia se instalaron particularmente en avenidas y edificios considerados estratégicos. A pesar de esto, la videovigilancia entró en la escena pública con mayor fuerza sólo tras la muerte del niño James Bulger. ${ }^{1}$ Este acontecimiento legitimó la presencia de la videovigilancia en el espacio público y abrió las puertas para que formara parte del paisaje urbano. De esta manera, el Reino Unido -y particularmente Londres- se convirtió en el referente de la sociedad videovigilada (Fussey, 2007). Con el tiempo, las cámaras de vigilancia se han afianzado -más aún con los atentados terroristas en Nueva York, en 2001- como una pieza fundamental del funcionamiento de las ciudades a escala global. Incluso, poco a poco se ha ido consolidando la idea de que las videocámaras optimizan la intervención gubernamental en distintas esferas de la vida social, más allá del combate al crimen y el terrorismo.

La presencia de las videocámaras pareciera garantizar, para algunos, las condiciones adecuadas para la inversión, el comercio y el consumo (Coleman y Sim, 2000). Esto es

I. James Bugler fue un pequeño de veinticuatro meses asesinado después de ser secuestrado y torturado por una pareja de niños de diez años (Robert Thompson y Jon Venables) en un poblado cercano a Liverpool. La detención y el juicio de los homicidas se sustentó en buena parte en las imágenes que se obtuvieron del circuito cerrado de televisión del centro comercial donde se llevó a cabo la abducción de Bugler y de distintos puntos de la ciudad por donde caminaron los asesinos en compañía de su víctima.

\section{4}


claro en los nodos financieros de la economía global como Nueva York, Londres, Tokio, París o Moscú (Coleman, 2004). Por tanto, su instalación respalda y cristaliza la idea que se tiene de una ciudad segura. En años recientes, los proyectos inmobiliarios han comenzado a incluir cámaras de vigilancia como parte del diseño de conjuntos arquitectónicos, a tal grado que casi cualquier proyecto de inversión urbana demanda la presencia de una red de videocámaras de vigilancia. Por ejemplo, la realización de eventos masivos de referencia mundial-como olimpiadas o torneos de futbolexige a las ciudades sede la instalación de infraestructura en este sentido (Samatas, 2004).

Actualmente, América Latina se ha convertido en uno de los nichos de crecimiento más importantes de la industria de estos dispositivos electrónicos a escala global (Mattelart, 2007). Según el reporte del IMS Research (2014), el mercado de la videovigilancia en América Latina mantuvo una tasa de crecimiento del 40.5\% desde el 2008 hasta el 2013, y, según las previsiones hechas en dicho reporte, se espera que esa tasa se mantenga cuando menos hasta el 2019. De hecho, se considera que para ese año la venta de dispositivos de videovigilancia llegará a los USD $200000000 .^{2}$

El crecimiento del mercado de la videovigilancia en América Latina se encuentra por encima de otras regiones del mundo, en parte apuntalado por Brasil como sede, en sólo diez años, de dos eventos deportivos globales. Más allá del caso brasileño, Argentina Colombia y México, encabezan los mercados con mayor crecimiento. En el caso de este último país, por ejemplo, la industria de cámaras de vigilancia incrementó sus ventas significativas entre 2011 y 2012 en

2. Desafortunadamente, informes más actuales del IMS Research son, por política de la empresa, inaccesibles para la academia. Para acceder a ellos se requiere formar parte de un buró de ventas internacionales relacionado con la industria de la vigilancia. Los datos que se presentan aquí están circunscritos al año 2013 con previsiones a 2019. 
un 60\%, (Manufactura, 2012) y mantuvo un crecimiento moderado hasta 2014, cuando se detuvo sensiblemente por la introducción de las cámaras de vigilancia digital -lo cual implicó un reacomodo en las finanzas de las empresas y los distintos ámbitos del Gobierno, quienes no estaban presupuestalmente preparados para adquirir estos equipos de última generación (Securitic, 2015). ${ }^{3}$ Sin embargo, el mercado volvió a repuntar en el 2015, una vez que las entidades públicas y privadas ajustaron sus presupuestos para adquirir la nueva tecnología digital de videocámaras (Securitic, 2015). Además, dado que el Subsidio para la Seguridad Pública en los Municipios (SUBSEMUN) contempla un rubro específico para la compra de videocámaras, las empresas esperan que en los próximos años se incremente nuevamente la venta de dicho artefacto.

Hay que señalar, sin embargo, que el incremento de la videovigilancia en México -y en general en América Latinano se ha hecho acompañar, como en otros lados, de una evaluación sobre su efectividad para hacer frente a la inseguridad, lo cual contrasta con el cúmulo de investigaciones al respecto en otros países, donde se han logrado establecer, por ejemplo, los límites y alcances de las cámaras de vigilancia en la prevención, reducción y reconstrucción de hechos criminales (Smith, 2012).

Además, estos estudios han mostrado que las cámaras de vigilancia tienen efectos en otros ámbitos de la vida social y no solamente en aspectos relacionados con la seguridad pública. Por un lado, tienden a desdibujar las fronteras que dividen la esfera de lo público y lo privado, colocando en no pocas ocasiones los datos personales que administran en un espacio de indeterminación jurídica. Por otro lado, la videovigilancia genera procesos de clasificación social y espacial que derivan en formas de exclusión de grupos

3. Se recomienda ver informe Securitic (20I5).

\section{6}


y sectores de población. Como sugiere Graham (2010), al separar espacios y zonas privilegiadas -las que necesitan protección-de aquellas que representan un riesgo -donde se produce la violencia y el crimen-, las cámaras de vigilancia resultan dispositivos que reproducen la desigualdad social y la segregación del espacio urbano.

Las voces que reclaman la instalación de un número mayor de cámaras de vigilancia pasan a veces por alto los efectos que estas producen en el derecho a la privacidad y en el ejercicio de la ciudadanía, así como su peso en los procesos de exclusión urbana y social, lo cual es aún más grave en contextos donde la violencia ha propiciado profundas fracturas sociales, ya que ante el imperativo de garantizar la seguridad a toda costa las instituciones incrementan la demanda de información de la población catalogada como potencialmente peligrosa, al mismo tiempo que exacerban los procesos de segregación urbana con el fin de diferenciar más claramente los espacios "seguros" de los "inseguros".

Abrir la discusión a este otro rostro de la videovigilancia resulta difícil en el caso de México porque, como en otras partes del planeta, se ha convertido en un elemento central de la narrativa sobre la gestión de riesgos (Barnard-Willis, 2011). En esta narrativa, las cámaras aparecen como la respuesta -si bien no la única, sí la mejor-a los problemas de inseguridad: la medida simbólica más efectiva contra el problema que representa el crimen y la delincuencia (Norris, 2012), lo que a mediano y largo plazo puede terminar, si no se tiene el cuidado adecuado, por debilitar a la ciudadanía -es decir, la capacidad que tienen los individuos de construir espacios de autonomía y control de sus vidas frente a las lógicas de estratificación y dominación (Held, 1989)-, ya que la vigilancia merma de alguna suerte esa capacidad al incrementarse las capacidades de los centros de poder y gestión urbana para clasificar o tipificar grupos sociales 
con el fin de promover políticas de control y modelación de comportamientos.

Si bien es cierto existen regulaciones que dan soporte a la ciudadanía frente al uso de la videovigilancia, aquellas son pobres o débiles en el caso mexicano, lo cual mina en ciertos aspectos la capacidad de las personas y grupos para hacerse de espacios de autonomía y control frente a procesos de clasificación y discriminación social. Incluso ahí donde existen regulaciones a la videovigilancia se puede observar, como apunta Cockfield (2011), que dichas regulaciones centran su atención en los temas relativos a la privacidad y la protección de datos personales -lo que no es menor-, pero dejan de lado los efectos sociales de la vigilancia.

El argumento central del presente trabajo es que la videovigilancia en México se considera regularmente sólo como una herramienta o dispositivo socio-técnico orientado a reforzar las políticas de seguridad, lo que deriva en un nulo interés por regular su funcionamiento, y cuando excepcionalmente se ha hecho esto las regulaciones no garantizan plenamente a los ciudadanos -como se tratará de mostrar- el marco adecuado para hacer frente a las lógicas de estratificación y dominación que derivan de su operación. En otras palabras, la poca normatividad sobre la videovigilancia deja en claro el desinterés por atender sus posibles efectos en la sociedad.

El texto abre con un panorama general de la videovigilancia en México, con el fin de mostrar su expansión a nivel nacional, estatal y municipal, así como el campo de controversias que se ha desarrollo a su alrededor. Posteriormente, se abordan los pocos intentos por establecer su regulación. Se analizan las leyes de Aguascalientes, Colima, Distrito Federal y Durango, y los reglamentos de los municipios de Guadalajara y Sayula, ambos en Jalisco. Se examina cómo su diseño está orientado a la protección de datos personales y la privacidad, y cómo dejan de lado la regulación de sus 
posibles efectos en los procesos de clasificación y tipificación de grupos sociales. En la tercera parte, se toman en consideración algunos resultados de investigaciones en el país que muestran cómo estos procesos de clasificación generan dinámicas de discriminación y exclusión social. Se teje, a continuación, una discusión de carácter más teórico sobre el impacto de estos dispositivos electrónicos en la construcción de la ciudadanía y la democracia. Finalmente, en el apartado de reflexiones finales se sugieren algunas recomendaciones generales para dar cuerpo a una agenda de intervención normativa sobre el particular.

\section{Videovigilancia en México: espacios de indeterminación}

El Censo nacional de Gobierno, seguridad pública y sistema penitenciario estatales 2015 reportó que veintinueve entidades federativas y el Distrito Federal tenían bajo su control 25631 cámaras de vigilancia para el ejercicio de la función de seguridad pública -más del doble de las que reportó ese mismo censo en 2012 (11 112 cámaras)-. ${ }^{4}$ El 41\% de las cámaras instaladas en el país se encuentran en el Distrito Federal (10 597 cámaras) - una cifra significativa, pero en descenso si se considera que en el 2012 concentraba el 74\% de las cámaras del país-. Detrás del Distrito Federal sigue el Estado de México -con 6135 dispositivos-, Guanajuato -con 2188 sistemas de videovigilancia-y Michoacán -que cuenta con 1296 cámaras-.

La diferencia entre la Ciudad de México y estas tres entidades habla de la disparidad en la distribución de la videovigilancia en el país, aunque es importante apuntar que para el censo del 2012 en su conjunto estas entidades no reunían más de cien cámaras. No obstante, es impor-

4. Datos que proporcionaban las administraciones públicas estatales y el Distrito Federal al cierre de $201 \mathrm{I}$ y 2013. 
tante considerar que hay estados, como Campeche, que al día de hoy cuenta con pocos dispositivos (ver Cuadro 1). Si bien estos datos permiten tener un panorama general de la presencia y crecimiento de la videovigilancia en el país, lo cierto es que no muestran cómo se ha expandido su uso en el ámbito municipal. De hecho, los grandes corporativos de la industria de la vigilancia ven a los municipios de México como el nicho de mercado con mayor crecimiento en los próximos cinco años. ${ }^{5}$

\section{Cuadro 1. Cámaras de vigilancia para el ejercicio} de la función de seguridad pública

Entidades federativas y Ciudad Cámaras de vigilancia para el ejercicio de México de la función de seguridad pública

\begin{tabular}{lr} 
Aguascalientes & $*$ \\
Baja California & 92 \\
Baja California Sur & 42 \\
Campeche & 25 \\
Coahuila & 32 \\
Colima & $*$ \\
Chiapas & $*$ \\
Chihuahua & 113 \\
Distrito Federal & 8308 \\
Durango & 74 \\
Guanajuato & $*$ \\
Guerrero & 142 \\
Hidalgo & 48 \\
Jalisco & 597 \\
México & 65 \\
Michoacán & 28 \\
Morelos & 105 \\
Nayarit & 60 \\
Nuevo León & 289 \\
Oaxaca & 30 \\
Puebla & 53 \\
\hline
\end{tabular}




\begin{tabular}{lc}
\hline $\begin{array}{l}\text { Entidades federativas y Ciudad } \\
\text { de México }\end{array}$ & $\begin{array}{c}\text { Cámaras de vigilancia para el ejercicio } \\
\text { de la función de seguridad pública }\end{array}$ \\
\hline Querétaro & 45 \\
Quintana Roo & 9 \\
San Luis Potosí & 193 \\
Sinaloa & 93 \\
Sonora & 189 \\
Tabasco & 45 \\
Tamaulipas & 20 \\
Tlaxcala & $*$ \\
Veracruz & 173 \\
Yucatán & 242 \\
Zacatecas & $*$ \\
Total nacional & 11112 \\
\hline
\end{tabular}

Fuente: INEGI $(2013 ; 2015)$.

Municipios de la zona metropolitana de la Ciudad de México como Atizapán, Huixquilucan, Ecatepec, Nezahualcóyotl, Naucalpan y Tlalnepantla han establecido redes de vigilancia por cámaras -de igual manera que en la capital del Estado de México (Arteaga, 2010a)-. ${ }^{6}$ Otros municipios localizados en el centro del país, como Puebla, instalaron en el 2015 aproximadamente quinientas setenta y seis videocámaras (E-Consulta, 2015), y se espera que para el 2016 se instalen cuatrocientas más para el corredor turístico y gastronómico de esa ciudad (Capital Puebla, 2015). Querétaro, por su parte, contaba con trescientas cincuenta y ocho cámaras de vigilancia (Diario Rotativo, 2015), y el municipio de Tlaxcala con cuarenta, esto en el 2013 (Tlaxcala Capital,

6. Aquí conviene suscribir una breve nota metodológica. No existe un censo sobre las cámaras de vigilancia que se usan en el ámbito municipal. Se recurre aquí a otro tipo de fuentes no tan precisas, pero que permiten comprender a grosso modo la importancia que adquiere la videovigilancia en los Gobiernos municipales. Se recurrió a dos tipos de fuentes: I) información periodística-declaraciones sobre la instalación de cámaras y entrevistas a autoridades locales-; y 2) informes de Ayuntamientos. Como apunta Davis (2007), en el caso del análisis de las políticas públicas en materia de seguridad en México, los recursos periodísticos son un elemento clave ante la falta o precariedad de información oficial. 
2015), mientras que en Cuernavaca se instalaron en ese mismo año setenta y siete (Zona Centro Noticias, 2015).

En el norte del país, municipios como Ciudad Victoria tenían quinientas tres cámaras de vigilancia en el año 2015 (Milenio Tamaulipas, 2016), mientras que Hermosillo instaló ciento treinta cámaras en la ciudad el mismo año (Ayuntamiento de Hermosillo, 2015). Torreón, por su parte, cuenta con doscientas veinte cámaras de vigilancia (Milenio Laguna, 2015). En Tijuana se tenían instalados setecientos dispositivos en el conjunto del entramado urbano en el 2015, además de que se destinaron cámaras personales por cada policía (Secretaría de Seguridad Pública de Tijuana, 2015).

En otros municipios se han instalado apenas algunas cámaras, como en el caso de Coatzacoalcos, donde se reportaron veinticuatro para el 2015 (Formato Siete, 2015). Otro ejemplo es Mérida, que cuenta sólo con sesenta y nueve cámaras de videovigilancia en los mercados Lucas de Gálvez y San Benito, así como en el centro de la ciudad (H. Ayuntamiento de Mérida, 2011). Oaxaca tiene reportadas sólo treinta y siete cámaras (Quadratin Oaxaca, 2015). Puerto Vallarta puso en operación treinta y seis en agosto de 2015 (Vallarta Noticias, 2015).

En municipios del sureste, como Tuxtla Gutiérrez, se tienen instaladas doscientas treinta cámaras, algunas de las cuales cuentan con sistema de reconocimiento facial, conectadas a un servidor con capacidad para administrar más de ochocientas cámaras (Imagen del Golfo, 2013).

Acapulco es un caso que muestra la dinámica de crecimiento de las cámaras de vigilancia a nivel municipal. En el año 2009 contaba sólo con veintitrés cámaras (H. Ayuntamiento de Acapulco de Juárez, 2010); dos años después tenía veintinueve (H. Ayuntamiento de Acapulco de Juárez, 2012); y, para 2015, contaba ya con quinientas setenta y cinco, todas ellas controladas por el Gobierno del estado de Guerrero (Bajo Palabra, 2015). A este apretado 
recuento habría que agregar la presencia de los regímenes privados de videovigilancia, que imperan en zonas residenciales cerradas, centros comerciales, empresas, parques de diversiones, entre otros espacios, lo cual garantiza que el mercado de videovigilancia siga creciendo (Anixter, 2011).

De esta manera, en distintas ciudades del país las cámaras de vigilancia se han convertido en parte de las políticas de seguridad y prevención. Han jugado un papel central dentro de las políticas de recuperación de espacios en las ciudades, así como de las políticas de renovación urbana orientadas a fortalecer la infraestructura y las atracciones turísticas, y a elevar la calidad de vida (ampliando el sentimiento de cuidado y protección entre la población). Por tanto, las cámaras de vigilancia no sólo funcionan como mecanismos para resolver y prevenir hechos criminales: son también dispositivos de gobierno que expresan reglas que buscan garantizar y gestionar el orden y la convivencia en las ciudades.

No obstante, también es cierto que la videovigilancia ha recibido críticas de diferente tipo. Por un lado, se le ha cuestionado su capacidad para resolver, como se esperaba, crímenes de figuras importantes en la vida política nacional -como sucedió con el asesinato del hermano del expresidente Carlos Salinas de Gortari en el municipio de Huixquilucan (Arteaga, 2007)-, o porque resulta una herramienta poco útil para enfrentar en tiempo real las acciones coordinadas del crimen organizado (por ejemplo, en mayo de 2013 fueron secuestradas once personas que se encontraban en un bar de la Ciudad de México, y las videocámaras no detectaron la movilización que desplegó el crimen organizado para realizar la operación -Arteaga, 2015-).

Además se ha criticado que las cámaras de vigilancia son utilizadas por las autoridades policiales en colusión con el crimen organizado (véase lo que sucedió en Acapulco, cuando los operadores de las cámaras monitoreaban al Ejér- 
cito y la Marina, transmitiendo la información a los grupos criminales vinculados al narcotráfico) (CNN-México, 2011). También el sistema ha recibido críticas al funcionar como mero testigo del horror de la violencia, por ejemplo, cuando se filmó el asesinato de una activista en Ciudad Juárez frente al Palacio de Gobierno (Radio Quintana Roo, 2013), o cuando sólo sirvieron de mudos testigos del secuestro de los estudiantes de la escuela normal de Ayotzinapa por parte de policías municipales y narcotraficantes.

También han surgido cuestionamientos que señalan lo costoso de su administración. En Tijuana, por ejemplo, fue durante un tiempo imposible sostener financieramente el sistema de videovigilancia (Zeta, 2013), mientras que en Querétaro, cuando se complicó su mantenimiento, el 50\% de las cámaras dejó de funcionar (El Universal Querétaro, 2013). En otros casos, se ha criticado el evidente uso de estos dispositivos como mecanismos de control político durante protestas sociales -hay que revisar su papel en el desalojo de comerciantes del mercado más importante de la ciudad de Toluca (Arteaga, 2010a)-.

Finalmente, algunos más han subrayado los procesos de estigmatización social que derivan del mal uso de la información que se obtiene de la videovigilancia. Al respecto, cabe poner como ejemplo los disturbios y comportamientos calificados como antisociales atribuidos a un grupo de reggaetoneros en el año 2012. ${ }^{7}$ Las imágenes captadas durante los disturbios fueron proporcionadas a las televisoras más importantes del país para su difusión, lo que contribuyó a reforzar la tipificación de estos jóvenes como peligrosos.

Pese a estas críticas, la videovigilancia goza de buena salud en la opinión pública. Según una encuesta, los mexicanos -al igual que los brasileños y los húngaros-consideran

7. Los reggaetoneros es un movimiento de barrios populares en la Ciudad de México adscritos al movimiento musical reggaeton, mezcla de reggae, hip-hop e influencias del Caribe latinoamericano. 
que las cámaras de vigilancia son efectivas para minimizar la inseguridad en el espacio público (ver Cuadro 2), una apreciación que se confirma cuando los medios de comunicación difunden -con autorización de los Gobiernos estatales y municipales- imágenes capturadas por las cámaras en las que se muestra el modus operandi de delincuentes, la disuasión de delitos, o su peso para respaldar procesos judiciales. ${ }^{8}$

Cuadro 2. Porcentaje de confianza de la población hacia la videovigilancia

\begin{tabular}{|c|c|c|c|c|c|c|c|}
\hline & 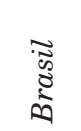 & 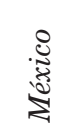 & 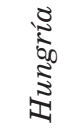 & 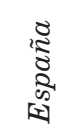 & 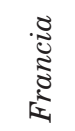 & $\begin{array}{l}\vec{D} \\
\dot{2} \\
\text { 섭 }\end{array}$ & 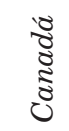 \\
\hline $\begin{array}{l}\text { Confianza en la } \\
\text { efectividad de la } \\
\text { videovigilancia } \\
\text { para minimizar la } \\
\text { violencia }\end{array}$ & $80 \%$ & $81 \%$ & $87 \%$ & $75 \%$ & $65 \%$ & $71 \%$ & $66 \%$ \\
\hline
\end{tabular}

Fuente: Ipsos (2006).

En este sentido, la difusión de los supuestos beneficios de las cámaras parece obviar en la opinión pública cualquier discusión sobre sus implicaciones sociales. Si a eso se suma que no existen criterios para evaluar el peso de las cámaras de vigilancia en el mejoramiento de la seguridad pública, además de que no se informan los criterios de operación y dónde se encuentran localizadas -bajo el argumento de que

8. Cuando se incrementan los cuestionamientos a la efectividad de las cámaras, las autoridades difunden algunos videos para legitimar la permanencia de su uso. Ver, por ejemplo, el caso de Tijuana, disponible en: http://www.diariobc.com/site/ index.php/mexicali/item/950-resultados-del-sistema-municipal-de-inteligencia-ymonitoreo-policial 
es información clasificada-, ${ }^{9}$ dichos sistemas de vigilancia constituyen regímenes de poder discrecionales y opacos.

Siguiendo a Agamben (2007), los órdenes no regulados de videovigilancia se constituyen en espacios de indeterminación jurídica. Cuando la videovigilancia queda a la deriva, funcionando con reducidos mecanismos de regulación, opera en sí misma como ley, ya que queda a la discreción de quien opera las cámaras decidir qué tipo de personas o colectivos deben ser monitoreados, qué tipo de información se recoge de ellos y cómo se debe almacenar, así como el tipo de uso que se le da a esa información.

Con ella se puede, además, clasificar, tipificar y etiquetar a ciertas personas o grupos sociales en función de sus comportamientos o identidades, las cuales pueden ser catalogas como potencialmente disruptivas para un cierto ambiente u orden social. La clasificación social genera efectos en el ejercicio de los derechos humanos en la medida en que ciertas personas y colectivos entran en un proceso de escrutinio particular marcado por los prejuicios construidos a su alrededor -los cuales pueden derivar, como sugiere Cockfield (2011), en la implementación políticas de exclusión social-. El hecho de que una persona o un grupo de personas esté en el foco de atención de un sistema de videovigilancia por el lugar que ocupa en un sistema de clasificación social afecta el ejercicio de su ciudadanía ya que, como sugiere Lyon (2007), se le trata de forma diferente de aquellos que

9. Cabe señalar sobre este punto que algunas organizaciones de la sociedad civil en México están llevando a cabo levantamientos de información sobre la localización de las videocámaras ante la negativa de las autoridades por mostrar su ubicación (bajo el argumento de que mostrar esa información implica atentar contra la seguridad). Particularmente, véase el caso de la ciudad de Mérida, Yucatán, donde distintas organizaciones han decidido transparentar la ubicación de las videocámaras. El levantamiento de la información puede verse en: http://www. informaciondelonuevo.com/20 I4/04/camaras-de-videovigilancia-en-merida_5. html, y la negativa de la autoridad puede revisarse en: http://es.scribd.com/ doc/I2744I594/Camaras 
han sido clasificados o tipificados como grupos que no son una potencial amenaza a la seguridad o el orden social.

Videovigilancia regulada: experiencias estatales y municipales

Son pocas las leyes y reglamentos estatales o municipales que regulan la videovigilancia en México (Ibarra, 2012; Téllez, 2012). En términos generales, centran su objetivo en dos aspectos: a) garantizar que la información que recogen sirva como elemento de prueba para castigar faltas administrativas y penales; y b) evitar las posibles violaciones al derecho de privacidad.

En cada una de las reglamentaciones que se analizan se subraya, por un lado, la necesidad de expandir la videovigilancia para respaldar la investigación y prosecución de hechos criminales, la sanción de faltas administrativas, y agilizar la intervención en tiempo real de la policía y la recolección de información para el diseño de políticas públicas.

Por otro lado, sin embargo, se resalta la obligación de cuidar que la videovigilancia no vulnere ciertas garantías individuales y derechos ciudadanos. En este sentido, se le define, aunque sólo sea de manera implícita, como una actividad que no es exclusivamente de orden administrativo, sino que pone en juego la relación entre el aparato gubernamental y el ejercicio de la ciudadanía.

La forma en cómo se trata de resolver esta doble lógica de la videovigilancia varía en cada uno de los documentos que la regulan en el país. No obstante, se definen por lo regular tres esferas de intervención: 1) la que tiene que ver con las áreas de responsabilidad y decisión; 2) relativa a la gestión y uso de las cámaras; y 3) la relacionada con el manejo de imágenes y sonidos que se recolectan o graban (ver Cuadro 3). 


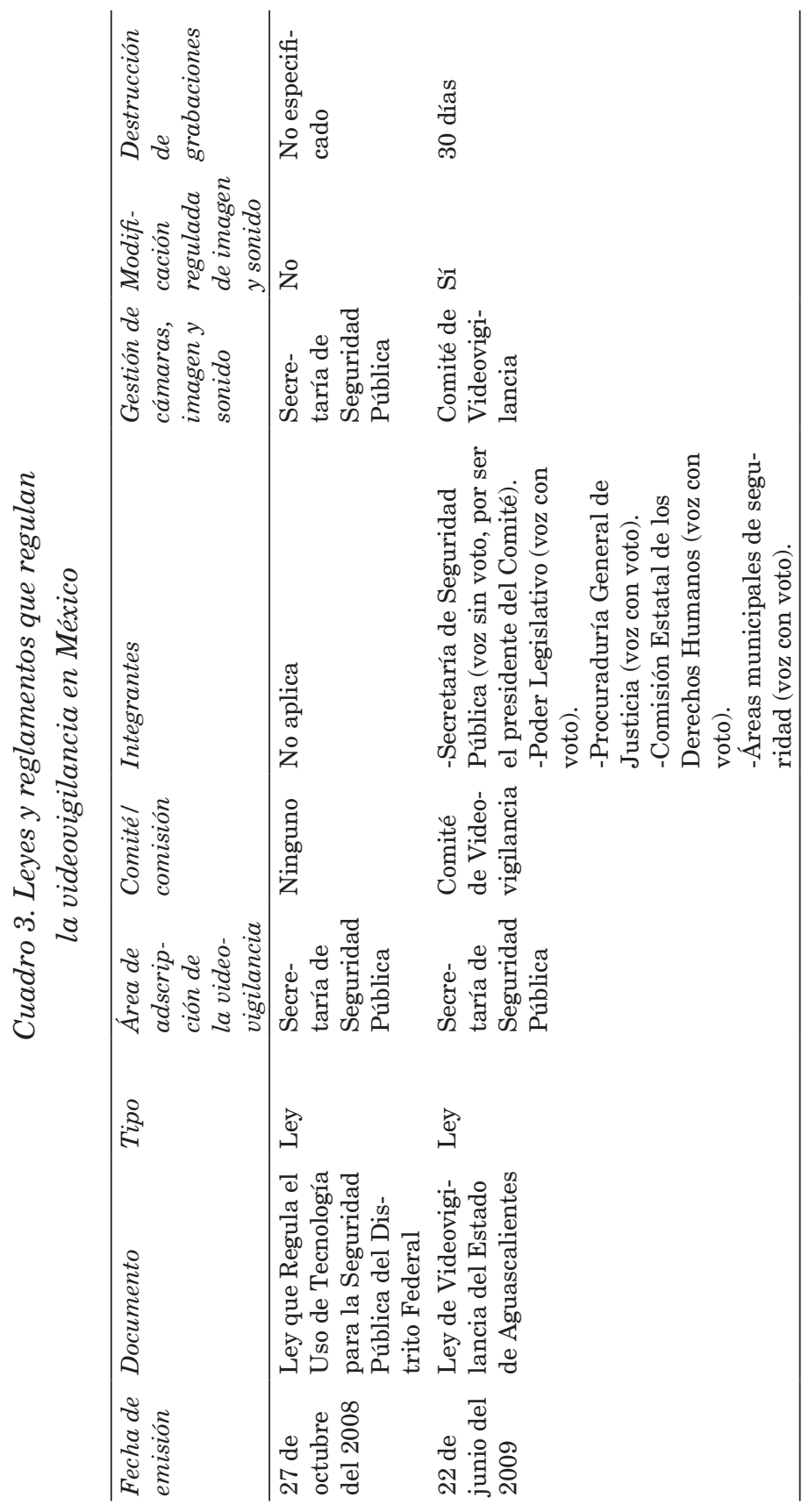




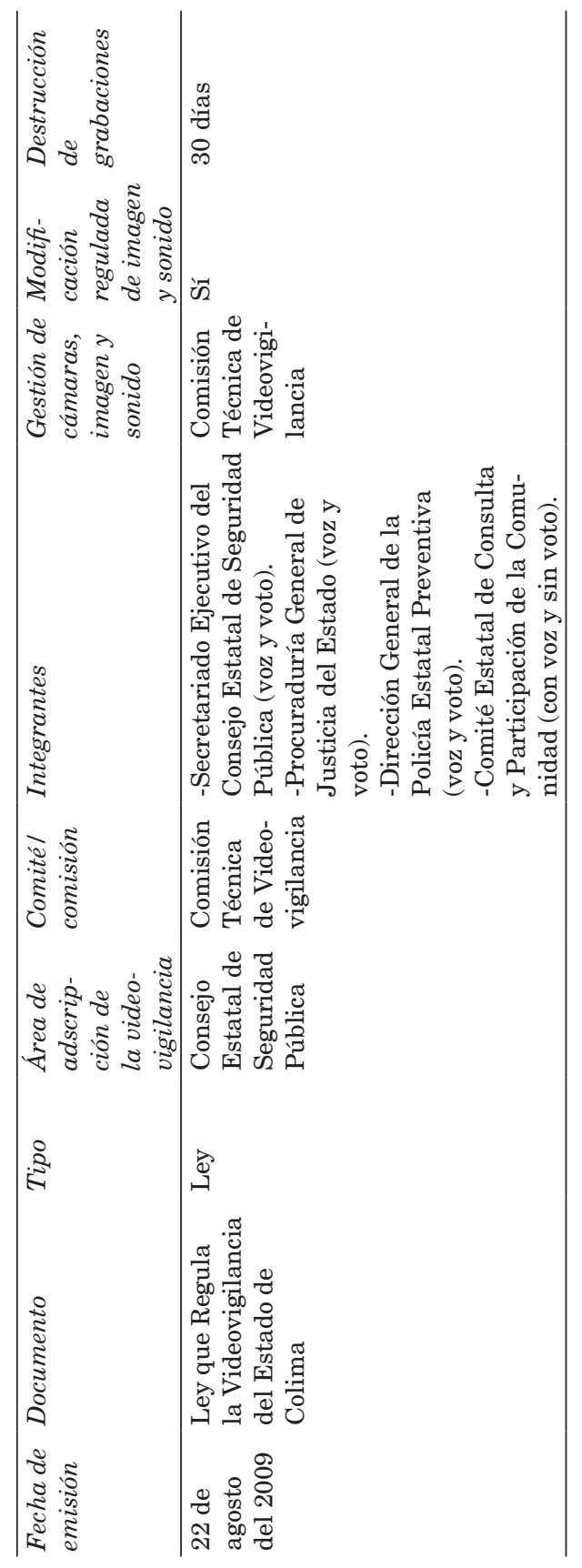

Sociedad $€$ No. 66 


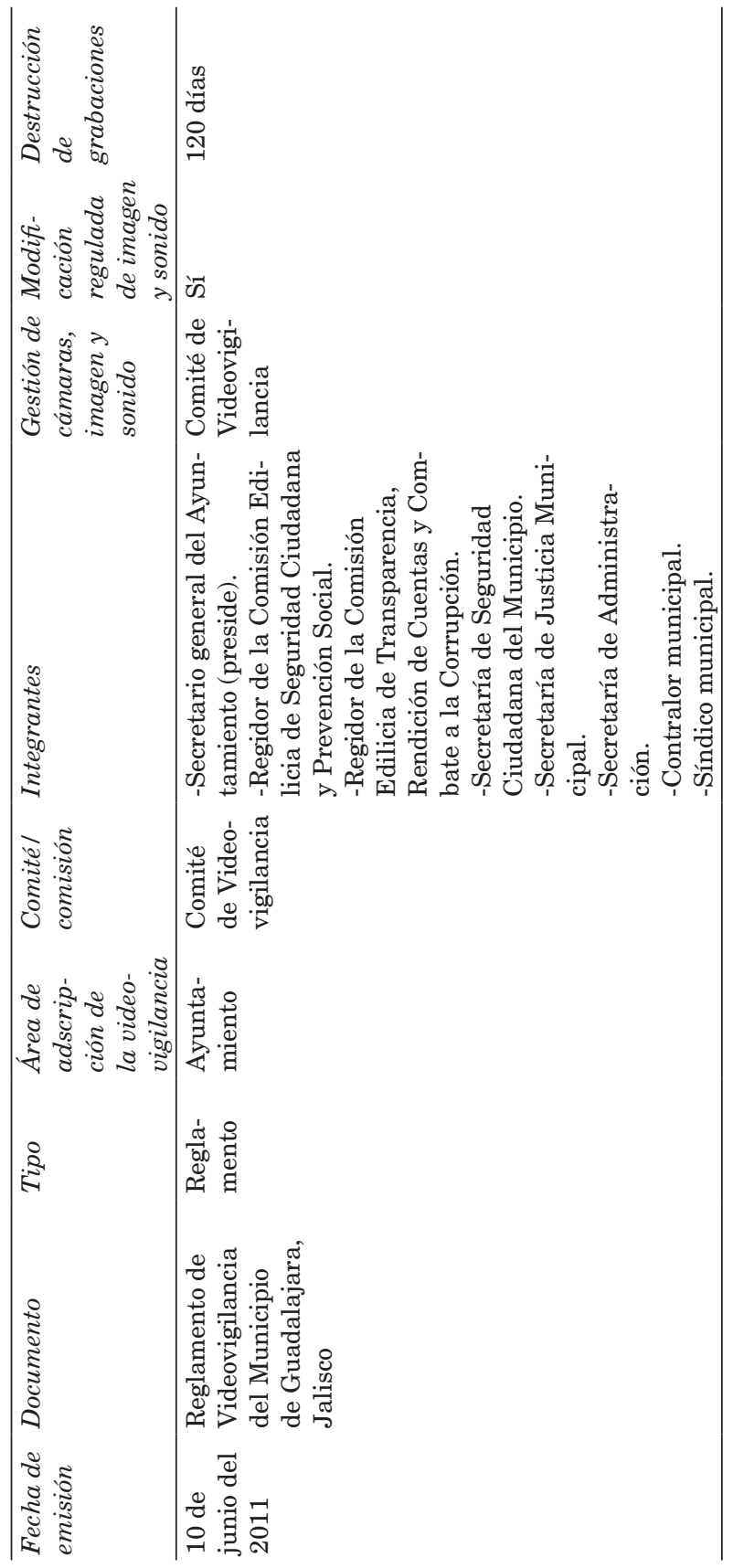




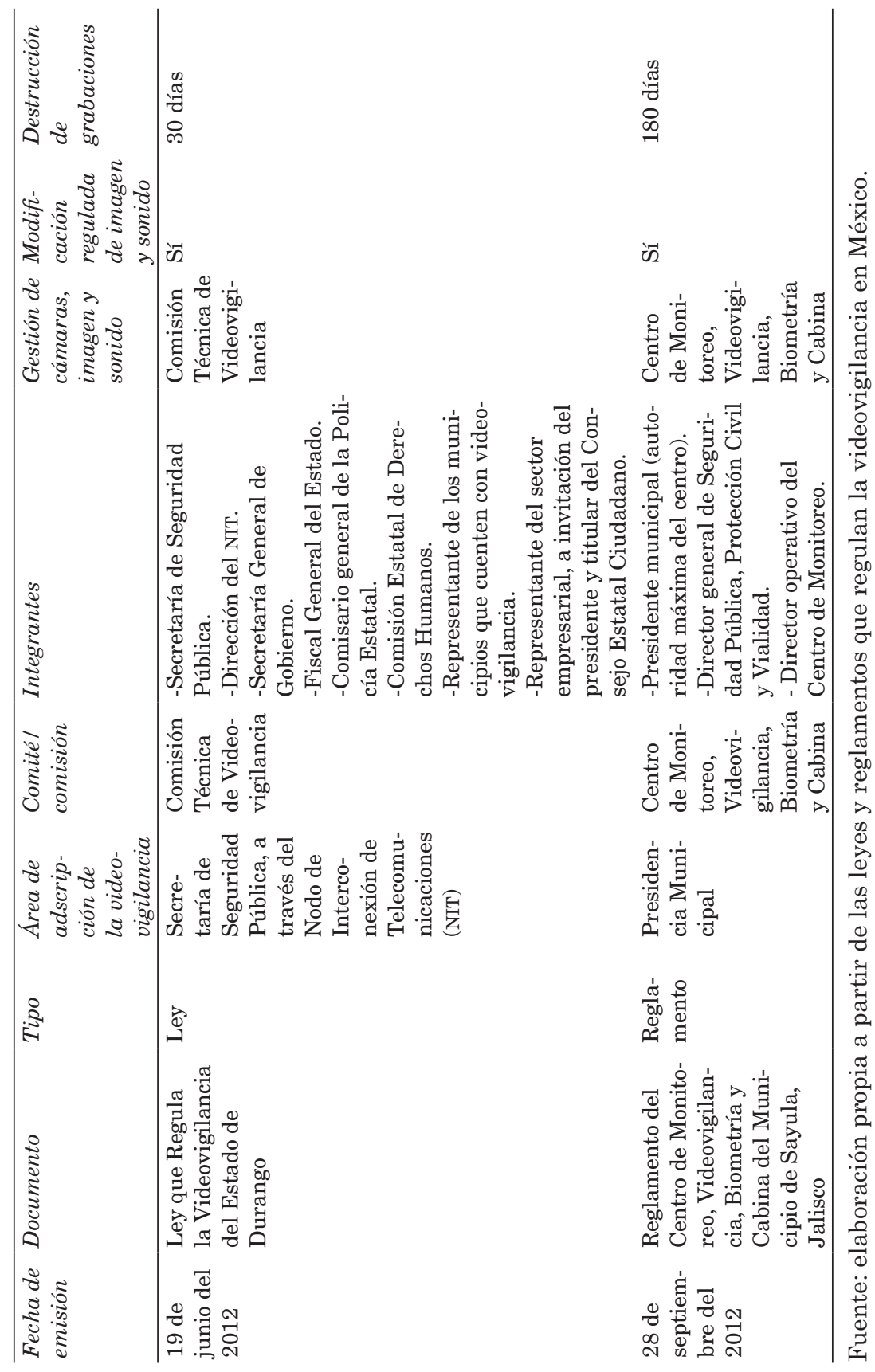

Sociedad $E$ No. 66 
Respecto a la primera esfera, las leyes de Durango, Colima y Aguascalientes, así como el reglamento de la ciudad de Guadalajara, plantean la constitución de comités o comisiones conformadas por distintos organismos gubernamentales. En ellos participan las instancias encargadas de la seguridad pública, la impartición de justicia, transparencia y Gobierno, así como de protección de derechos humanos y diversas formas institucionalizadas de participación ciudadana -como consejos empresariales-. Sólo en los casos de la Ciudad de México y el municipio de Sayula no hay presencia de mecanismos de decisión gubernamental de este tipo. En el primer caso, la Secretaría de Seguridad Pública está a cargo completamente de la videovigilancia, mientras que en el caso de Sayula está bajo la responsabilidad y el control directo del presidente municipal.

Con relación a la gestión y uso de las cámaras de videovigilancia, las leyes de Durango, Colima y Aguascalientes, y los reglamentos de Guadalajara y Sayula definen su instalación y operación a partir de los criterios de proporcionalidad, tanto por su idoneidad -que contribuya a consolidar un clima de seguridad-, como por su intervención mínima -que en su uso no se afecten los derechos de intimidad, honor e imagen-. De igual forma, se considera necesario que la instalación pondere criterios razonables de control de riesgos -que garanticen su prevención-, así como de peligro concreto - cubierto por la instalación de videocámaras móviles para enfrentar contingencias inminentes-.

Estos criterios no aplican, en cada una de las leyes y reglamentos, cuando se pretende vigilar los espacios privados e íntimos, salvo consentimiento del propietario u orden judicial. ${ }^{10}$ En este sentido, la instalación de las cámaras de

10. Pese a que estas leyes y reglamentos buscan regular la videovigilancia a nivel estatal y municipal, lo hacen pensando en el uso que se da a las cámaras fijas. Las de tipo móvil caen prácticamente fuera de cualquier regulación. Su uso está sujeto a la discreción de las autoridades de seguridad pública y, aunque después se exige 
vigilancia se define a partir de contrapuntear estos criterios con las propuestas de instalación y monitoreo que derivan de los diagnósticos estatales y municipales en materia de prevención, inhibición y atención de conductas penales o faltas administrativas, según sea el caso. En estos diagnósticos, se pondera por lo regular la instalación de cámaras en zonas consideradas de alta incidencia delictiva, áreas que presentan una alta concentración de población, o en avenidas y calles con un elevado flujo vehicular y de transeúntes. No obstante, si se vulneran la privacidad y los derechos fundamentales de los ciudadanos, las leyes y reglamentos establecen los criterios para su remoción.

La ley de la Ciudad de México se distingue de las otras en el país porque trata de definir los criterios de instalación de videocámaras de vigilancia a partir de la sistematización de información criminal, dejando de lado, al menos en la ley, los criterios de proporcionalidad e intervención mínima. Considera, por tanto, las tendencias en la estadística delictiva -a nivel de vecindarios, manzanas, avenidas y calles-, las áreas con el mayor reporte de infracciones a automovilistas, y aquellas que presentan riesgos en caso de fenómenos de origen natural.

Se apoya para esto en la información que proporciona la Procuraduría de Justicia y la Subsecretaría de Control de Transito. ${ }^{11}$ No obstante, considera otro tipo de fuentes: reportes del ministerio público, policía, índices de percepción de la inseguridad, información contenida en el Atlas delincuencial y de riesgo, así como los registros de denuncias telefónicas. De esta forma, son diversas las fuentes para definir la instalación de las cámaras de vigilancia.

a las comisiones un reporte sobre las imágenes y sonidos grabados, existe aquí un vacío legal entre el momento en que se instalan y el aviso a las autoridades sobre los objetivos que han motivado el despliegue de las cámaras móviles.

I I. En la Ciudad de México, la Secretaría de Seguridad Pública del Distrito Federal sólo cuenta con un comité asesor en materia de tecnología para la seguridad, el llamado Consejo Asesor en Ciencia y Tecnología para la Seguridad Pública. 
En el manejo de imágenes y sonidos, las leyes y reglamentos delinean tres ámbitos de intervención: 1) la protección de la privacidad y datos personales; 2) la fidelidad de las grabaciones; y 3) la destrucción de la información.

En el primer caso, se establece la necesidad de garantizar la protección de los datos personales de la población videograbada proporcionando resoluciones a las solicitudes de información. Incluso, cuando el caso lo amerita, las leyes de Durango, Aguascalientes y Colima, así como en el reglamento de Guadalajara, tienen contemplado borrar o hacer ilegibles las imágenes de personas identificadas o potencialmente identificables.

En el segundo ámbito de intervención, se pone especial atención en la inalterabilidad de las imágenes y sonidos con el fin de que sean un soporte robusto como prueba de cargo en delitos y faltas administrativas. Se establece que cualquier modificación voluntaria o involuntaria de las grabaciones -exceptuando las relativas a la protección de la identidad-invalida en automático la información como prueba cargo o acusación.

Finalmente, se contempla la necesidad de borrar las grabaciones después de un determinado tiempo, el cual es variable. En algunos casos, se establece el periodo de un mes, en otros hasta de seis meses. Estos tres ámbitos de intervención quedan bajo la responsabilidad de los distintos comités, cuando es el caso, o de las instancias encargadas de la seguridad pública.

Particularmente en la Ciudad de México, destaca la existencia de un protocolo detallado denominado "cadena de custodia" de las grabaciones. Este es un documento oficial en el que se asienta la forma en cómo se obtuvo la información, qué funcionarios tuvieron acceso a ella y con qué objetivos. Esto permite establecer candados sobre la inviolabilidad e inalterabilidad de las grabaciones, garantizando su conservación y cuidado. 
De esta forma, quienes hayan tenido acceso a la información deben otorgar por escrito una promesa de confidencialidad que respetarán, incluso después de haber dejado de laborar en la institución. En la medida en que los hechos y sonidos que son captados por las cámaras de vigilancia están considerados como prueba en los procedimientos judiciales y penales, se deben señalar los medios de su obtención, su origen y las circunstancias en las cuales se capturó. Además, se deben establecer por escrito los elementos visuales de la grabación, incluyendo la transcripción de los elementos sonoros. La cadena de custodia garantiza, por tanto, que la información no ha sido alterada por ningún motivo y en ningún momento.

Como se puede observar, las leyes y reglamentos que regulan la gestión de la vigilancia en México tienen una serie de rasgos comunes: tratan de balancear el escrutinio de la vida de sus ciudadanos en los espacios públicos con la protección de su privacidad; definen también los criterios para instalar las cámaras y gestionar las imágenes y sonidos que graban, asegurando su inalterabilidad y, con el paso del tiempo, su destrucción; de igual manera, establecen las entidades responsables de la gestión de la videovigilancia.

No obstante, difieren en cada caso en la forma en cómo esto debe llevarse a cabo. Por lo que se refiere a las áreas de responsabilidad y decisión, se encuentran dos tendencias: las que consideran la necesidad de crear comités o comisiones gubernamentales, y las que concentran la gestión plena de la videovigilancia en una sola instancia de gobierno.

Cuando las leyes y reglamentos se inclinan por la primera figura, resalta la falta de protocolos específicos de gestión. Sucede todo lo contrario con la segunda figura -como en los casos de la ley del Distrito Federal y el reglamento del municipio de Sayula-. En este sentido, parece ser que cuando existen mecanismos colegiados de decisión no hay una preocupación por desarrollar normatividades y protoco- 
los específicos. ${ }^{12}$ Aunque estos últimos existan en contextos centralizados de videovigilancia, eso no garantiza que se cumplan a cabalidad, sobre todo si no hay contrapesos y contrapartes institucionales que verifiquen su cumplimiento.

La gestión de la videovigilancia parece también definirse por dos vías en las leyes y reglamentos sobre la materia. Por un lado, destacan los criterios de carácter normativo, como los de proporcionalidad e intervención mínima; por otro lado, se encuentran los criterios basados en estadísticas e información criminal. ${ }^{13}$

En el primer caso, las cámaras se instalan, desinstalan o se desplazan en función de los derechos de privacidad y protección de datos personales, lo que complica la gestión de la videovigilancia porque no se prevé ningún tipo de diagnóstico como base para una estrategia definida para su instalación. Cuando esto llega a suceder, como en el caso de la Ciudad de México, se hace con criterios diversos.

En ambos casos, los mecanismos de gestión hacen difícil una evaluación del impacto de las videocámaras en la reducción del crimen y la delincuencia, e incluso complican medir en qué proporción se afecta la privacidad y los datos personales de los ciudadanos.

Un asunto similar sucede, finalmente, con el manejo de imágenes y sonidos. El conjunto de las legislaciones estatales considera algún criterio de protección de los mismos. En algunos casos se contempla su manipulación -con vista a salvaguardar la privacidad y datos personales-. La figura del comité y comisión funciona como una instancia de

12. En la mayoría de los casos, las comisiones o comités deben presentar un reporte periódico que permita evaluar el desempeño de los dispositivos (en algunos casos mensualmente, $y$ en otros cada tres meses).

13. Es claro que los dos criterios aquí señalados no se contraponen de manera tajante, pero los diagnósticos parecen estar subordinados, al menos en la legislación, a los criterios de proporcionalidad e intervención mínima. En el caso de la Ciudad de México, la legislación contempla la localización de las videocámaras utilizando sólo criterios estadísticos e información policial.

\section{6}


deliberación intergubernamental -aún limitada por la escasa participación de la sociedad civil- para discutir la gestión de las imágenes y sonidos, mientras que en el caso de la Ciudad de México la cadena de custodia es la vía que la Secretaría de Seguridad tiene para hacerlo.

Las legislaciones y reglamentaciones en torno a la videovigilancia en México instituyen relaciones diferenciales entre vigilantes y vigilados. Aun cuando esto represente un avance con respecto a aquellos municipios y estados donde la vigilancia funciona como ley, lo cierto es que aún quedan zonas grises en la forma en cómo se articulan los espacios de responsabilidad y decisión sobre la gestión de la videovigilancia y el manejo de imágenes y sonidos que genera.

Por otro lado, hay que resaltar que las leyes y los reglamentos que existen en el país centran su atención en los aspectos de la privacidad y los datos personales, soslayando hasta cierto punto el posible impacto de la videovigilancia en las dinámicas de clasificación, segregación y discriminación social. Es decir, no se considera en las leyes y reglamentos en México la manera en que las tecnologías de la vigilancia contribuyen a fortalecer los procesos de categorización y posible tratamiento diferencial de ciertos grupos y personas.

Hay que recordar que aquellos que tienen la capacidad de potenciar las formas de clasificación social tienden a encontrarse en posiciones relevantes de poder y control (Lyon, 2007). Ciertamente, los procesos de clasificación social en categorías son parte sustancial de cualquier sociedad (Goffman, 1970). Permiten la identificación y diferenciación de personas con el fin de ubicarlas en un grupo social específico. Las personas tienden a clasificar a otras personas a partir de una serie de características específicas, como, por ejemplo, su vestimenta, habla, comportamiento o lo que consumen (Lyon, 2007). Al estar colocadas en una posición privilegiada, las cámaras de vigilancia pueden abarcar un amplio número de personas que cubren las categorías consi- 
deradas como potencialmente peligrosas o desorganizadoras de cierto orden social.

Si las distintas legislaciones estatales sobre la videovigilancia dejan al margen de la agenda social este potencial riesgo que implica el uso de videocámaras, dejan de lado también el hecho de que esas formas de clasificación y tipificación social pueden ser un factor que genere el tratamiento diferencial de ciertos grupos sociales y, en algunos casos, la puesta en marcha de procesos de exclusión social.

\section{Más allá de la privacidad y los datos personales}

Las legislaciones y normas vigentes en el país con relación a la videovigilancia centran su atención en un importante número de temas ligados a su instalación y gestión, así como a la administración de datos. Sin embargo, como ya se señaló, no toman en consideración el hecho de que pueden generar procesos de exclusión social y segregación de ciertos sectores sociales del espacio urbano.

La literatura sobre el tema ha enfatizado en distintos momentos que la vigilancia, si bien puede reforzar procesos de seguridad y bienestar - por tanto, dinámicas sociales de inclusión-, también puede propiciar lo opuesto: la sobreexposición a la vigilancia de ciertas personas por su color de piel, vestimenta o comportamiento con el fin de mantener una supervisión particular sobre ellos (Senior, 2009; Heilmann, 2008; Koskela, 2006; Ball y Webster, 2003).

Como ya se señaló, cualquier sociedad genera procesos de inclusión y exclusión social a partir de la tipificación o clasificación de grupos o personas en función de su fisonomía o por la forma en cómo visten o se comportan (Goofman, 1986). La videovigilancia resulta una tecnología particularmente poderosa porque incrementa la capacidad de la mirada humana para distinguir y diferenciar socialmente ciertos tipos sociales (Klauser, 2007; Barreto y Leite, 2010),

\section{8}


por ejemplo, en una plaza comercial, parque o en una calle concurrida, donde ciertas personas o grupos cumplen con una serie de atributos sociales que se considera pueden generar una disrupción en el orden social.

En este sentido, la operación de la videovigilancia está determinada por el carácter humano de los operadores, quienes orientan la vigilancia hacia aquellas personas y comportamientos que consideran como sospechosos o inusuales (Lyon, 2007; Norris, Moran y Armstrong, 1998). Esto pone de relieve el hecho de que la operación de las cámaras se encuentra de cierta manera alimentado por prejuicios y tipificaciones anclados en texturas culturales específicas (Lakoff y Klinenberg, 2010), lo cual sugiere que las cámaras no siempre funcionan observando de forma homogénea al conjunto de la sociedad (Hier, Walby y Greenberg, 2006).

Más bien, la vigilancia se acentúa en los sectores tradicionalmente considerados como posibles responsables de alterar o poner en riesgo el desarrollo normal de la vida social (Lianos, 2010). Si bien esto está presente en las formas tradicionales de gestión de la seguridad, la videovigilancia permite, como sugiere Norris (2003), expandir las capacidades de gestión de la población desde ciertos centros de poder (Klauser, 2007) y limitar con ello la capacidad que tienen los individuos de construir espacios de autonomía y control de sus vidas frente a esas lógicas de estratificación y dominación.

A continuación, se presentan algunos ejemplos que buscan ilustrar estos mecanismos de exclusión social con el fin de poner atención a este aspecto relegado de la legislación y normatividad en materia de videovigilancia.

El primero de ellos se extrae de un trabajo realizado en el centro de control de las cámaras de vigilancia en la zona residencial de Interlomas, localizada en el municipio de Huixquilucan, Estado de México (Arteaga, 2007). La investigación mostró cómo los operadores de la policía municipal 
tienden a monitorear de forma particular a los trabajadores de la construcción cuando arriban a trabajar en los edificios que se construyen en la zona, así como en la tarde, es decir, al momento en que estos regresan a sus casas.

El monitoreo que se hace sobre estos grupos de trabajadores se justifica, en voz de sus operadores, porque son personas que potencialmente pueden cometer algún tipo de ilícito, sobre todo introducirse en algún edificio para robar o asaltar. Para estos operadores, cualquier persona que camina por las calles de esta zona habitacional requiere de cierto monitoreo, ya que es inusual que los habitantes del lugar hagan uso de las calles para caminar. Si la persona que se encuentra caminando en la calle parece que no tiene un comportamiento considerado como normal-no se dirige hacia un lugar específico, camina de un lado hacia a otro-, se envía una patrulla para ayudarlo a salir de Interlomas. ${ }^{14}$

El segundo ejemplo deriva de un trabajo realizado en el conjunto arquitectónico conocido como Reforma 222, en la ciudad de México. A los pocos días de su inauguración, los sistemas de videovigilancia funcionaron para detectar y prevenir que miembros de la comunidad lésbico-gay se besaran o abrazaran en el centro comercial del edificio (Arteaga, 2016). Las cámaras permitían monitorear estos comportamientos y, una vez detectados, los cuerpos de seguridad pedían a las personas que se comportaran de otra manera, y si se negaban, se les invitaba a salir del lugar. A través de redes sociales, los miembros de la comunidad se organizaron para resistir a estas formas de vigilancia y

14. Cuando se realizó el trabajo, se pudo constatar que los encargados del centro de operación del sistema de videovigilancia invitaban a los alumnos de las escuelas secundarias públicas del municipio a visitar las instalaciones -la totalidad de ellas fuera de Interlomas- para advertirles que si venían a esa zona residencial y hacían una cosa "mala", quedaría grabada y podría servir como prueba para detenerlos, mientras que a los alumnos de las escuelas privadas de la zona se les decía que las cámaras estaban instaladas para garantizar su protección y seguridad (Arteaga, 2007). 
discriminación, hasta que forzaron a la administración del lugar a frenar la forma en como estaban gestionando ese espacio.

Sin embargo, estos no han sido procedimientos excepcionales de exclusión social (Arteaga, 2010c). Se ha podido observar este tipo de uso de las cámaras en otros espacios donde autoridades municipales, por ejemplo, establecen el monitoreo de personas de la comunidad lésbico-gay en plazas públicas, a quienes se les sugiere dejar el lugar o no comportarse de una forma "anormal" o "inadecuada". También se usa la videovigilancia para evitar que vendedores ambulantes, niños que piden limosna o prostitutas se asienten y transiten en plazas públicas o zonas consideras turísticas, bajo el pretexto de garantizar la imagen del lugar.

A esto hay que añadir el hecho de que las imágenes que se recogen, almacenan y procesan en los centros de videovigilancia pueden ser reproducidas en la televisión, en distintas plataformas de internet -como Youtube- o en redes sociales. Esto genera una conexión particular entre medios de comunicación e imágenes recogidas por los sistemas de videovigilancia, en el que ambos se retroalimentan permanente (Andrejevic, 2007; Denzin, 1995; Mathiesen, 1997).

Las cámaras de vigilancia proporcionan las imágenes que respaldan las narrativas que refuerzan los estereotipos y clasificaciones sobre grupos sociales que se considera pueden alterar de alguna forma cierto orden social (Lyon, 2006; Haggerty, 2009; Lippert y Wilkinson, 2010). En este sentido, es común observar en los noticiaros del país cómo se sobreexponen una serie de imágenes de presuntos delincuentes adscritos a ciertos grupos sociales, lo cual tiende a reproducir los estereotipos sobre quiénes son los responsables de la delincuencia y otros comportamientos tipificados como inciviles.

Siguiendo a Schinkel (2010), si consideramos que existen dos tipos de ciudadanías, una formal y la otra moral -una 
que refiere al estatus jurídico; la otra, al marco normativo extrajudicial de lo que un buen ciudadano "debe" o "debería ser" (Schinkel y Van Houdt, 2010)-, ciertas imágenes que se obtienen de los sistemas de videovigilancia y que se transmiten por los medios de comunicación tienden a marcar la pauta para juzgar la ciudadanía moral de ciertos grupos sociales, dando mayor peso a los aspectos morales y condicionando a mediano plazo la pervivencia de los de carácter formal.

Esto dibuja una ciudadanía donde las determinantes jurídicas son desplazadas por valores sustentados en un difuso y cambiante marco moral (Lippert, 2009), lo cual, por supuesto, acelera los procesos de clasificación y categorización social, que pueden minar la capacidad de ejercicio de la ciudadanía formal, limitando sus capacidades para enfrentar las lógicas de estratificación y dominación moral que se imponen sobre los ciudadanos.

\section{Videovigilancia: democracia y tecnologías} de la información

Las tecnologías de la información han generado cambios significativos en el ejercicio de la ciudadanía. Despliegan, en un primer momento, innovadoras relaciones entre personas y grupos sociales; en un segundo momento, instituyen formas particulares de colectar, almacenar y procesar información por parte de agencias gubernamentales y corporaciones privadas.

Sin embargo, las tecnologías no funcionan bajo una racionalidad propia o a partir de un imperativo del que es difícil escapar. Son más bien puentes que conectan la cultura con la estructura social (Bell, 1991). La videovigilancia es uno de esos puentes que une el problema de la inseguridad -como expresión de las tensiones y contradicciones de la estructura 
social- con nuestra percepción o idea de cómo enfrentarlo -inscritas en nuestras texturas culturales-.

En este sentido, como otras tecnologías que permiten el monitoreo de amplios sectores de la población, la videovigilancia introduce cambios significativos en el ejercicio de la ciudadanía: incorpora en un mismo espacio digital la gestión de datos personales con la clasificación y tipificación de grupos sociales y sus comportamientos. Fusiona así los temas de la privacidad y los derechos ciudadanos con el cuidado y el bienestar de las personas y grupos.

La videovigilancia va más allá de los confines de la privacidad o la protección de datos personales en los que se movió algún día el debate sobre la sociedad de la información. Su operación impacta el desarrollo de la vida democrática y el bienestar, en la medida en que puede tanto vulnerar el derecho a la privacidad, la intimidad y la protección de datos personales como propiciar procesos de segregación social-al definir grupos sociales como targets-. Esto daña el ejercicio de ciertos derechos ciudadanos en la medida en que se mina la capacidad de las personas para hacer frente a las lógicas de clasificación y tipificación social que se imponen desde los aparatos de poder.

Gracias al imperativo que prevalece en la opinión pública de garantizar la seguridad pública a toda costa, la necesidad de un marco regulatorio para la videovigilancia parece que se encuentra en un segundo plano. Aunque es posible constatar la presencia de regulaciones a la videovigilancia, donde se procura normar la gestión de los datos y las imágenes, no hay una preocupación por evitar las dinámicas de exclusión social y discriminación que genera, no obstante que, como Lyon (2007) afirma, la transparencia en las sociedades de la videovigilancia es el tema central para garantizar la salud de la democracia y la dignidad humana.

La transparencia es necesaria para regular el apetito de las instituciones públicas y privadas por los datos per- 
sonales, el almacenamiento, procesamiento y difusión de imágenes. De igual forma, lo es para saber de qué forma se clasifica a las personas y los grupos sociales en el espacio urbano. Es necesaria para garantizar la libertad. La transparencia apunta a ubicar quién define y cómo se definen los criterios de la videovigilancia, un principio democrático que apela en última instancia a establecer mecanismos para vigilar a los que vigilan.

Los aparatos gubernamentales son propensos al "secuestro institucional de la experiencia social" (Giddens, 1991, p.144): sustraen ciertos fenómenos como el crimen, la enfermedad o la pobreza de su entorno social, colocándolos en su lógica de control, a veces sin ningún tipo de supervisión. Perciben a la sociedad como una externalidad sobre la que es necesario operar formas específicas de monitoreo para colectar información -a través de clasificar al mismo tiempo grupos y comportamientos- que pueda apoyar la definición de soluciones a problemas sociales.

En este sentido, la videovigilancia es un mecanismo socio-técnico que permite separar la violencia, el crimen o los comportamientos considerados como antisociales de su contexto social, proyectándolos en un mero plano informático donde las causas que provocan esos fenómenos pasan a un segundo plano. De esta forma, la instrumentalidad es el único criterio que la gobierna, desplazando a un segundo plano la discusión ética. Por eso no extraña que cuando se critican los posibles usos de la videovigilancia la respuesta de los funcionarios se reduce a señalar los logros que se han tenido, resaltando la eficiencia como el principio rector de su actuación. ${ }^{15}$

15. La autoridad a cargo de la videovigilancia en la Ciudad de México responde, ante el cuestionamiento de un periodista sobre la posible vulneración de datos personales o las dinámicas de segregación urbana que se pueden producir: "Las críticas son respetables, pero al final del día los resultados hablan, y lo que te puedo decir es que sólo grabamos lo que sucede en los espacios públicos, sin violar la intimidad de nadie" (Camacho, 20I3, p. 4I). Este es un ejemplo del 
Los criterios de efectividad, en un claro clima de inseguridad como el que vive el país, se colocan a veces por encima del derecho a la privacidad, el resguardo de los datos personales y los efectos en las relaciones sociales. La vigilancia es un medio de poder, como sugiere Giddens (1987), no importa la forma que adquiera, por lo que no debe estar desregulada.

Ciertamente, algunas cosas se han hecho en materia de regulación de la videovigilancia, pero resultan aún incipientes. Por ejemplo, el conjunto de leyes y reglamentos en el país consideran la necesidad de advertir a los ciudadanos que están bajo videovigilancia a través de un aviso, lo cual abre la puerta a la ciudadanía para intervenir en caso de que considere que su privacidad o datos personales están en riesgo. Sin embargo, sólo en el caso de Aguascalientes se obliga a suscribir en dicho aviso el nombre de la instancia responsable de la vigilancia, sus datos de contacto, además de las leyes y reglamentos a los que se puede apelar si se considera que los derechos de privacidad han sido violados.

El Instituto Federal de Acceso a la Información y Protección de Datos (IFAI) estableció en su comunicado IFAI/065/13 (7 de julio de 2013), un modelo de aviso de privacidad que podrá ser utilizado por los responsables de sistemas de videovigilancia. El aviso contempla los siguientes aspectos: nombre, denominación o razón social del responsable, domicilio del responsable, así como finalidades de la vigilancia.

Esto resulta un avance importante en la medida en que construye un espacio regulado no de forma abstracta, sino

discurso que manejan los operadores de cámaras de vigilancia en el país, quienes afirman constantemente que las cámaras se manipulan adecuadamente. Recuerda las afirmaciones que años atrás hacían las autoridades al respecto de la confianza que debería tener la sociedad con relación a los programas sociales, de que estos sólo llegan a quienes lo necesitaban realmente, sin ningún tipo de sesgo. Hay que recordar que una democracia se construye a partir de la regulación institucional y supervisión de quienes detentan un cargo. La confianza en un elemento esencial, aunque no suficiente, para la salud de la democracia. 
concreta, conectada a momentos y situaciones precisas en las que se pueden ver dañados la privacidad y los datos personales. ${ }^{16}$ Sin embargo, es evidente, por otro lado, que las cuestiones sociales quedan fuera, nuevamente, del espectro de la regulación de la videovigilancia. No obstante, es un avance que haya avisos que adviertan que un espacio está videovigilado, porque hacen saber a los ciudadanos que no sólo ellos están bajo una forma específica de Gobierno, sino que también lo están aquellos que se encuentran detrás de las cámaras.

\section{Reflexiones finales}

La videovigilancia está creciendo a pasos agigantados en el país. El discurso de la seguridad pública ha permitido su naturalización, sobre todo en los espacios urbanos. Sin embargo, su pobre o inexistente regulación ha derivado en la conformación de un archipiélago de regímenes de videovigilancia, donde marcos jurídicos diferenciales ponen en juego distintos ejercicios de ciudadanía y dinámicas específicas de segregación social o urbana. No resulta congruente que los habitantes de una ciudad tengan una cierta certeza jurídica frente a la videovigilancia, mientras que en otras ciudades no exista un marco claro de su funcionamiento. Es imprescindible establecer mecanismos normativos a nivel nacional, estatal y municipal que permitan definir criterios para el funcionamiento de videovigilancia.

En primer lugar, sería conveniente establecer una legislación federal que sirviera para enmarcar el funcionamiento de la videovigilancia a nivel nacional. Es necesario definir los criterios para instalar, administrar y gestionar la operación no sólo de la videovigilancia, sino de la información en

16. Dado que es una recomendación, no está sujeta a ser operada de manera obligatoria, por lo que no todos los sistemas de vigilancia han llevado esto a la práctica.

\section{6}


imágenes que esta genera. Se podría subrayar la necesidad no sólo de incluir los criterios de proporcionalidad, sino además los preceptos que permitan evitar la presencia de procesos de segregación urbana y exclusión social.

Esto significa que debe existir un diagnóstico previo que mida el impacto de la videovigilancia en la morfología del espacio urbano. Convendría incluir la necesidad de supervisar la operación de la videovigilancia para que no funcione por criterios de clasificación social discriminatorios. Dado que gran parte de los dispositivos de videovigilancia se encuentran en espacios urbanos, se deberá considerar el derecho de acceso a la ciudad como un criterio de su operación. La videovigilancia resulta pertinente cuando hay diagnósticos claros y precisos, garantizando que su desempeño sea susceptible de evaluación.

La vigilancia no puede quedar como un entidad opaca a cargo de las instancias de seguridad pública o, peor aún, a criterio de cada uno de los Poderes Ejecutivos en las entidades y de los alcaldes en los territorios municipales: se debe considerar la creación de comisiones estatales y municipales, según sea el caso, que estén al tanto de su operación.

La figura de comisiones o consejos deberá involucrar la participación tanto de las instancias gubernamentales pertinentes como de las comisiones de derechos humanos, así como abrir espacios a las organizaciones de la sociedad civil, en particular a aquellos sectores que son tendencialmente proclives a ser considerados como targets de la videovigilancia. Considerando estos elementos, se podría asegurar su funcionamiento claro y transparente. ${ }^{17}$ Dicha comisión deberá estar pendiente de que el sistema funcione y opere, garantizando además que las autoridades gubernamentales prevean su sustentabilidad técnica.

17. Una perspectiva de género debe resultar parte sustancial de la normatividad operativa en los centros de control, como bien sugiere Koskela (2012). 
Un aspecto importante a considerar es el tema de los avisos o advertencias colocados en los espacios videovigilados. Las leyes y reglamentos analizados, al igual que la reciente propuesta del IFAI sobre el particular, representan un avance significativo. Con todo, sería importante, como apuntan Clement y Ferenbok (2012), que las advertencias orienten e informen sobre las características de la videovigilancia, al tiempo que clarifiquen la legalidad y regulación a la que está sujeta. El primer conjunto debe proveer información sobre qué tipo de vigilancia se despliega, con qué objetivos, para qué fines, su operatividad, cuánto tiempo se almacenan las imágenes, los alcances técnicos (si cuenta con sistemas de reconocimiento facial y el software puede difuminar rostros), o si las imágenes son susceptibles de encriptación (Clement y Ferenbok, 2012).

Estas advertencias deberían contemplar, además, la prohibición del uso de las imágenes en medios de comunicación -a menos que hubiera de por medio una orden o permiso judicial-. Con esto, puede establecerse un mecanismo de transparencia en el que no se mermen los derechos ciudadanos ni la privacidad, pero que también dé pie a una participación colectiva en los procesos de videovigilancia.

Todas estas consideraciones legales y reglamentarias tendrían que ser obligatorias para que el propio SUBSEMUN y otros mecanismos de apoyo financiero otorguen recursos para la adquisición de sistemas de videovigilancia. Es claro que, independientemente de los temas que aquí se han abordado, la industria de la videovigilancia se mueve en buena parte gracias a recursos públicos. Por tanto, entregar recursos para acceder a estos dispositivos tiene que hacerse con el compromiso de que existe un mínimo de protecciones al ejercicio de la ciudadanía, y que no se responde exclusivamente a un discurso policial y sobre seguridad a ultranza.

La videovigilancia no puede ser expulsada de nuestra vida ni borrada del paisaje urbano porque sirve para proteger y 
cuidar a la población, pero es necesario imponerle límites. Saber quién vigila, con qué criterios y cómo se transforma esa observación sistemática en información es un paso esencial para fortalecer la democracia y evitar que la gestión de lo social termine siendo administrada por lógicas opacas de clasificación y tipificación de grupos social

Fecha de recepción: 20 de agosto de 2014 Fecha de aceptación: 19 de febrero de 2016

Agamben, G. (2007). Qu'est-ce qu'un dispositif? París: Éditions Payot \& Rivages.

Andrejevic, M. (2007). iSpy: Surveillance and Power in the Interactive Era. Kansas: University Press of Kansas.

Anixter (2015). El mercado latinoamericano de cámaras de seguridad crecerá un 39\% entre 201 l y 2014. Madrid: Anixter. Recuperado de: http://www.anixtersoluciones. com/latam/uy/informacion_general// 7584/el_mercado_latinoamericanio_de_camaras_de_seguridad_crecera_un_392_entre_20II_y_20I4_es.htm

Arteaga, N. (2007). "An Orchestration of Electronic Surveillance". International Criminal Justice Review, I7(4), 325-335.

(20/0a). “Urban Surveillance in Mexico”, en R. Firmino, F. Duarte, y C. Ultramari (eds.), ICTs for Mobile and Ubiquitous Urban Infrastructures: Surveillance, Locative Media and Global Networks (pp. 324-340). Lancaster: IGI. (20I0b). "Privacy and Surveillance in Mexico and Brazil: A Cross-National Analysis”, en E. Zureik, L. Stalker, E. Smith, D. Lyon, y Y. Chan (eds.), Surveillance, Privacy and the Globalization of Personal Information (pp. 2 12-229). Toronto: McGill-Queen's University Press. (2010c). "Video vigilancia del espacio urbano: tránsito, seguridad y control social”. Andamios, (14), 263-286. 
Bibliografía
(2012). "Surveillance Cameras and Synopticism. A case Study in Mexico City", en A. Doyle, R. Lippert, y D. Lyon (eds.), Eyes Everywhere. The Global Growth of Camera Surveillance (pp. 236-257). Londres: Routledge. (20I5). "Surveillance footage and space segregation in Mexico City”. International Sociology, 30(6), 619-636. (2016). "Securitization and urban space: a study from a skyscraper in Mexico City", en M. Backer, L. Melgaço, G. Varna, y F. Menichelli (eds.), Order and Conflict in Public Space (pp. 37-6I). Londres: Routledge. Bajo Palabra (20 de octubre de 20I5). "Sin funcionar desde hace tres años las cámaras de vigilancia en Acapulco". Recuperado de: http://bajopalabra.com.mx/sin-funcionar-desde-hace-3-anos-las-camaras-de-vigilancia-enacapulco/

Ball, K., y Webster, F. (2003). "The intensification of surveillance”, en K. Ball, y F. Webster (eds.), The Intensification of Surveillance: Crime, Terrorism and Warfare in the Information Age (pp. I-16). Londres: Pluto Press.

Barnard-Willis, D. (20I I). "UK News Media Discourses of Surveillance”. The Sociological Quarterly, 52(4), 495-620. Barreto, R., y Leite, M. (20I0). "Redes de vigilância: a experiência da segurança e da visibilidade articuladas às cameras de monitoramento urbano", en F. Bruno, M. Kanashiro, y R. Fermino (eds.), Vigilância e Visibilidad, Espaço, Tecnologia, Identificaçao (pp. 36-60). Porto Alegre: Editora Sulina.

Bell, D. (199I). The Winding Passage. Sociological Essays and Journeys. New Brunswick: Transaction Publishers.

Biber, K., y Dalton, D. (2009). "Making Art for Evidence: Secret Sex and Police Surveillance in the Tearoom". Crime, Media, Culture, 5(3), 243-267.

Camacho, F. (20I3). "Vigilar a través de cámaras, tendencial global de control y exclusión social”. La Jornada. Recu- 
perado de: http://www.jornada.unam.mx/2013/07/08/ sociedad $/ 04$ In I soc

Capital Puebla (30 de diciembre de 2015). "Preparan instalación de primeras cámaras de video-vigilancia". Recuperado de: http://www.capitalpuebla.com.mx/ puebla/preparan-instalacion-de-primeras-camaras-devideo-vigilancia

Clement, A., y Ferenbok, J. (20I2). "Mitigating Asymmetic Visibilities: Towards a Signage Code for Surveillance Camera Network", en A. Doyle, R. Lippert, y D. Lyon (eds.), Eyes Everywhere. The Global Growth of Camera Surveillance (pp. 309-332). Londres: Routledge.

CNN-México ( 15 de junio de 20 I I). "Cámaras policiales vigilaban instalaciones militares en Acapulco: Marina”. Recuperado de: http://mexico.cnn.com/nacional/201 I/06/I5/ camaras-policiales-vigilaban-instalaciones-militares-enacapulco-marina

Cockfield, A. (20II). "Surveillance as Law". Griffith Law Review, 20(4), 795-816.

Coleman, R. (2004). "Watching the degenerate: street camera surveillance and urban regeneration". Local Economy, 19(3), 199-211.

y Sim, J. (2000). “'You'll never walk alone': CCTV surveillance, order and neo-liberal rule in Liverpool city centre". British Journal of Sociology, 5 I (4), 623-639.

Davis, D. (2007). "El factor Giuliani: delincuencia, la "cero tolerancia' en el trabajo policíaco y la transformación de la esfera pública en el centro de la Ciudad de México". Estudios Sociológicos, 25(75), 639-68I.

Denzin, N. (1995). The Cinematic Society: The Voyeur's Gaze. Londres: Sage.

Diario Rotativo ( 13 de enero de 2015). "Operan en Querétaro 358 cámaras de videovigilancia”. Recuperado de: https:// rotativo.com.mx/noticias/metropoli/queretaro/3742 I3operan-en-queretaro-358-camaras-de-videovigilancia/ 
Bibliografía

Doyle, A., Lippert, R., y Lyon, D. (20I2). “Introduction”, en A. Doyle, R. Lippert, y D. Lyon (eds.), Eyes Everywhere: the global growth of camera surveillance (Pp. I-20). Nueva York: Routledge.

E-Consulta (03 de diciembre de 2015). "Suman 576 cámaras red de videovigilancia en Puebla". Recuperado de: http://www.e-consulta.com/nota/20 I5-12-03/seguridad/ suman-576-camaras-red-de-video-vigilancia-en-puebla

El Universal Querétaro (29 de abril de 2013). "Dan mantenimiento a las cámaras de videovigilancia". Recuperado de: http://www.eluniversalqueretaro.mx/ metropoli/29-04-20I3/dan-mantenimiento-camarasde-videovigilancia

Formato Siete (23 de diciembre de 2015). "Municipio de Coatzacoalcos instalará 20 cámaras de vigilancia”. Recuperado de: http://formato7.com/20 I5//2/23/municipiode-coatzacoalcos-instalara-20-camaras-de-vigilancia/

Fussey, P. (2007). "Observing Potentiality in the Global City: Surveillance and Counterterrorism in London". International Criminal Justice Review, I 7(3), I7I-192.

Giddens, A. (1987). The Nation-State and violence. Berkeley: University of California Press.

(I99I). Modernity and Self-Identity: Self and Society in the Late Modern Age. Cambridge: Polity.

Goffman, E. (1970). Estigma. La identidad deteriorada. Buenos Aires: Amorrortu.

(1986). Frame Analysis. An Essay on the Organization of Experience. Boston: Northeastern University Press.

Graham, S. (20I0). Cities under Siege: The New Military Urbanism. Nueva York: Verso.

H. Ayuntamiento de Acapulco de Juárez (2010). Primer Informe de Gobierno 2009-20 I 2. Acapulco de Juárez: H. Ayuntamiento de Acapulco de Juárez. 
H. Ayuntamiento de Acapulco de Juárez (20I2). Tercer Informe de Gobierno 2009-20 I 2. Acapulco de Juárez: H. Ayuntamiento de Acapulco de Juárez.

H. Ayuntamiento de Hermosillo (2015). Plan Municipal de Desarrollo 2013-2015. Hermosillo: H. Ayuntamiento de Hermosillo.

H. Ayuntamiento de Mérida (20II). Segundo Informe de Gobierno 2009-2012. Mérida: H. Ayuntamiento de Mérida. Recuperado de: http://yucatanahora.com.mx/ noticias/camaras-vigilancia-policia-municipal-instaladassin-permiso-del-inah-21/3/

Haggerty, K. (2009). "Ten Thousand Times Larger...: Anticipating the Expansion of Surveillance", en D. Neyland, y B. Goold (eds.), New Directions in Privacy and Surveillance (pp. 159- 177). Londres: Willan.

Heilmann, E. (2008). "La vidéosurveillance, une mirage technologique et politique”, en L. Mucchielli (ed.), La Frénésie Sécuritaire (Pp. I I3-124). París: La Découverte. Held, D. (1989). Political Theory and the Modern State. Cambridge: Polity Press.

Hempel, L., y Töpfer, E. (2009). “The Surveillance Consensus: Reviewing the Politics of CCTV in Three European Countries”. European Journal of Criminology, 6(2), I57177.

Hier, S., Walby, K., y Greenberg, J. (2006). "Supplementing the Panoptic Paradigm: Surveillance, Moral Governance and CCTV", en D. Lyon (ed.), Theorizing Surveillance: The Panopticon and Beyond (pp. 230-244). Cullompton: Willan Publishing.

Ibarra, E. (20I2). "Videovigilancia. Puntos de colisión entre derechos fundamentales y protección de datos personales en México", en E. Ibarra, y R. Romero (coord.), Jurismática. El derecho y las nuevas tecnologías (PP. 23I269). Monterrey: UANL. 
Bibliografía

IFAI (7 de julio de 20 I3). "Comunicado IfAI/065/I3”. México: IFAI.

Imagen del Golfo (12 de mayo de 2015). "Instalarán cámaras inteligentes en Tuxtla". Recuperado de: http://www. imagendelgolfo.com.mx/resumen.php?id=356898

IMS Research (2014). 2014 trends in video surveillance in Latin America. Nueva York: IMS Research.

INEGI (20I3). Censo nacional de Gobierno, seguridad pública y sistema penitenciario estatales 2013. México: INEGI.

- (20I5). Censo nacional de Gobierno, seguridad pública y sistema penitenciario estatales 2015. México: INEGI. Ipsos (2006). Global Privacy of Data: International Survey. Summary report commissioned by the Globalization of Personal Data (GPD) project, Queen's University, Kingston. Recuperado de: http://www.sscqueens.org/intl_survey_ background

Klauser, F. (2007). "Disturbance in the Sensory Experience of the City: CCTV and the Development of an Unreal Urban 'Parallel World”.'. Senses and Society, 2(2), 172188.

Koskela, H. (2006). "The other side of surveillance: Webcams, power and agency", en D. Lyon (ed.), Theorizing Surveillance: The Panopticon and Beyond (pp. 163-I8I). Cullompton: Willan Publishing. (20I2). "'You shouldn't wear that body' -the problematic of surveillance and gender", en K. Ball, K. Haggerty, y D. Lyon (eds.), Routledge Handbook of Surveillance Studies (pp. 49-56). Londres: Routledge.

Lakoff, A., y Klinenberg, E. (20I0). "Of Risk and Pork: Urban Security and the Politics of Objectivity". Theory and Society, 39(5), 503-525.

Lianos, M. (2010). "Periopticon: Control Beyond Freedom and Coercion", en K. Haggerty, y M. Samatas (eds.), Surveillance and Democracy (pp. 69-88). Nueva York: Routledge. 
Lippert, R. (2009). "Signs of the Surveillant Assemblage: Privacy Regulation, Urban CCTV, and Governmentality". Social \& Legal Studies, I8(4), 505-522.

y Wilkinson, B. (2010). "Capturing Crime, Criminals and the Public's Imagination: Assembling Crime Stoppers and CCTV Surveillance". Crime, Media, Culture, 6(2), $|3|-\mid 25$.

Lyon, D. (2006). "9/I I, Synopticon, and Scopophilia: Watching en Being Watched", en K. Haggerty, y R. Ericson (eds.), The new politics of surveillance and visibility (pp. 35-54). Toronto: University of Toronto Press.

(2007). "Surveillance, security and social sorting: emerging research priorities". International Criminal Justice Review, I7(3), I6I-170.

Manufactura (I4 de mayo de 20I2). "Videovigilancia crece en México". Recuperado de: http://www.manufactura.mx/ industria/20 I 2/05/ / 4/video-vigilancia-crece-en-mexico Mathiesen, T. (1997). “The Viewer Society: Michel Foucault's Panopticon Revisited”. Theoretical Criminology, I (2), 2I5-234.

Mattelart, A. (2007). La globalisation de la surveillance. Aux origenes de l'ordre sécuritaire. París: La Découverte.

Milenio Laguna (8 de marzo de 20I5). "Cerca de 220 cámaras de videovigilancia en Torreón". Recuperado de: http://www.milenio.com/region/camaras_de_videovigilancia_en_Torreon-Seguridad_Publica_de_Torreon_0_477552338.html

Milenio Tamaulipas (30 de enero de 2016). "Empieza vigilancia con 200 cámaras". Recuperado de: http:// www.milenio.com/region/Empieza-vigilancia-camaras_0_370I62988.html

Norris, C. (2003). "From personal to digital: CCTV, the panopticon, and the technological mediation of suspicion and social control”, en D. Lyon (ed.), Surveillance 
Bibliografía as social sorting: Privacy, risk and digital discrimination (Pp. 249-28I). Londres: Routledge.

(20I2). "There's no success like failure and failure's no success at all: some critical reflections on the global growth of CCTV surveillance", en A. Doyle, R. Lippert, y D. Lyon (eds.), Eyes Everywhere: the global growth of camera surveillance (pp. 23-45). Nueva York: Routledge.

Moran, J., y Armstron, G. (1998). "Algorithmic surveillance: the future of automated visual surveillance", en C. Norris, J. Moran, y G. Armstrong (eds.), Surveillance, closed circuit television and social control (pp. 255-276). Aldershot: Ashgate.

Quadratin Oaxaca (14 de octubre de 2015). "Instalarán 30 cámaras de seguridad en mercados tradicionales". Recuperado de: https://oaxaca.quadratin.com.mx/Instalaran30-camaras-de-seguridad-en-mercados-tradicionales/

Radio Quintana Roo (03 de julio de 2013). "Asesinan a activista enfrente de palacio de gobierno de Ciudad Juárez". Recuperado de: http://radioquintanaroo.com/ asesinas-en-protesta-a-activista-enfrente-del-palaciode-gobierno-de-ciudad-juarez/

Samatas, M. (2004). Surveillance in Greece. From Anticommunist to Consumer Surveillance. Nueva York: Pella.

Schinkel, W. (2010). "The Virtualization of Citizenship". Critical Sociology, 36(2), 265-283.

- y Van Houdt, F. (2010). "The double helix of cultural assimilationism and neo-liberalism: Citizenship in contemporary governmentality". The British Journal of Sociology, 6 I (4), 696-7I5.

Secretaría de Seguridad Pública de Tijuana (2015). Cámaras personales para cada policía. Tijuana: Secretaría de Seguridad Pública de Tijuana. Recuperado de: http:// policiatijuana.gob.mx

Securitic (05 de enero de 2015). "Videovigilancia, un negocio con grandes expectativas en 2015". Recuperado de: 
http://www.securitic.com.mx/reportaje-especial/33Bibliografía videovigilancia/reportaje// 397-videovigilancia-unnegocio-con-grandes-expectativas-en-20I5

Senior, A. (2009). "An introduction to Automatic Video Surveillance", en A. Senior (ed.), Protecting Privacy in Video Surveillance (pp. 35-48). Nueva York: Springer.

Smith, G. (20I2). "What goes up, mist come down: on the moribundibity of camera networks in the UK", en A. Doyle, R. Lippert, y D. Lyon (eds.), Eyes Everywhere: the global growth of camera surveillance (pp. 46-66). Nueva York: Routledge.

Téllez, J. (20I2). "La regulación jurídica de la videovigilancia bajo una perspectiva de derecho comparado", en E. Ibarra, y R. Romero (coords.), Jurismática. El derecho y las nuevas tecnologías (pp. 270-285). Monterrey: UANL.

Tlaxcala Capital (09 de febrero de 20I5). "Delincuencia disminuyó en $80 \%$ en Tizatlán, durante 20I4: Sánchez Santos". Recuperado de: http://www.capitaltlaxcala. gob. $m x /$ ? $=2904$

Vallarta Noticias (04 de julio de 20I5). "Implementa Puerto Vallarta operativo Verano Seguro 2015”. Recuperado de: http://vallartanoticias.com/2015/07/implementapuerto-vallarta-operativo-verano-seguro-20 I5/

Zureik, E. (2010). "Cross-Cultural Study of Surveillance and Privacy: Theoretical and Empirical Observations", en E. Zureik, L. Stalker, E. Smith, D. Lyon, y Y. Chan (eds.), Surveillance, Privacy and the Globalization of Personal Information (Pp. 348-360). Toronto: McGill-Queen's University Press.

Stalker, L., Smith, E., Lyon, D., y Chan, Y. (2010). Surveillance, Privacy and the Globalization of Personal Information. Toronto: McGill-Queen's University Press. Zeta (22 de enero de 2013). "El fraude de las cámaras". Recuperado de: http://www.zetatijuana.com/html/Edicion I 776/Reportajez_EIFarudeCamaras.html 
Bibliografía Zona Centro Noticias (II de mayo de 2015). "Buscará ayuntamiento de Cuernavaca instalar 50 cámaras de vigilancia más en el municipio". Recuperado de: http://www.zonacentronoticias.com/20 I5/05/buscaraayuntamiento-de-cuernavaca-instalar-50-camaras-devigilancia-mas-en-el-municipio/ 